\title{
Risk management as a social defence against anxiety
}

\author{
Authors: \\ Dirk J. Geldenhuys ${ }^{1}$ \\ Madia M. Levin ${ }^{1}$ \\ Annelize van Niekerk ${ }^{1}$ \\ Affiliations: \\ ${ }^{1}$ Department of Industrial \\ and Organisational \\ Psychology, University of \\ South Africa, South Africa \\ Correspondence to: \\ Dirk Geldenhuys \\ Email: \\ geldedj@unisa.ac.za \\ Postal address: \\ PO Box 392, Unisa 0003, \\ South Africa \\ Dates: \\ Received: 06 May 2011 \\ Accepted: 26 Oct. 2011 \\ Published: 20 Mar. 2012 \\ How to cite this article: \\ Geldenhuys, D.J., Levin, \\ M.M., \& Van Niekerk, A. \\ (2012). Risk management \\ as a social defence against \\ anxiety. SA Journal of \\ Industrial Psychology/SA \\ Tydskrif vir Bedryfsielkunde, \\ 38(2), Art. \#982, 9 pages. \\ http://dx.doi.org/10.4102/ \\ sajip.v38i2.982
}

C 2012. The Authors. Licensee: AOSIS OpenJournals. This work is licensed under the Creative Commons Attribution License.
Orientation: This article deals with the unconscious role of risk management in an African country.

Research purpose: The aim of the study is to describe how risk management unconsciously influences behaviour when doing business in an African country.

Motivation for the study: Operational risk management is a rational management imperative. However, this does not take cognisance of the unconscious role of risk management. A systems-psychodynamic perspective might be particularly relevant if the anxiety implied in risk management is not appropriately contained. Awareness of these dynamics may provide an opportunity for addressing them and allow for a more holistic way of managing risk.

Research design, approach and method: The researchers conducted the study as a qualitative case study in an African country. They used purposive sampling and analysed the data using qualitative content analysis.

Main findings: Viewing risk management from a systems-psychodynamic perspective allowed the researchers to identify the influence of risk management on the behaviour of people. The emerging hypothesis was that, if businesses do not address the anxiety underlying risk management, managing risk becomes a social defence against the anxiety.

Practical/managerial implications: Awareness of the anxiety involved in risk management may assist businesses to manage risk in a more realistic way, making provision for, and even capitalising on, the human element.

Contributions/value-add: The article provides a systems-psychodynamic, and hence a more complete, perspective of operational risk management when doing business in an African country.

\section{Introduction \\ Key focus of the study}

Banks would be out of business in Africa if they did not take risks. However, if they take risks without managing them in appropriate and comprehensive ways, banks might also be out of business! Taking risk is inherent to any business endeavour (Hubbard, 2009) and the economic recession has highlighted the importance of managing it (Butler, 2010). Risk management lies at the core of the operations of financial institutions and is a strategic activity (Andersen, 2006). Managers drive risk management and employees adhere to it (Jain, 2010).

This study viewed risk management from a systems-psychodynamic perspective. Its focus was the influence of anxiety on implementing a risk management framework in a South African financial institution that does business in an African country.

\section{Background to the study}

Banks and financial institutions face an environment that increasing regulatory requirements, technological innovation and growing competition characterises. This reality, from an operational point of view, has resulted in a greater possibility of failure. This, in turn, has resulted in an increased focus on managing risk (Jain, 2010).

The Basel Committee (2006) defines operational risk as the risk of loss that results from inadequate or failed internal processes, people and systems or from external events. Regulators of financial 
companies and banks are demanding a greater awareness of the risks banks manage and the effectiveness of the controls they have in place to reduce possible losses.

Compliance regulations, like Basel II, mandate a focus on operational risks. They compel financial organisations to control and manage risk. This has led to an increased emphasis on the importance of having a sound operational risk management (ORM) framework in place. To comply with Basel II requirements, banks make significant investments to improve their internal risk processes, data infrastructures and analytical capabilities by employing the advanced measurement approach (AMA). The AMA fosters a risksensitive environment and promotes efficiency in managing risk from an operational point of view (Jain, 2010). However, with the focus on increasing regulatory requirements and technological innovation, the behavioural aspects related to risk management are under-researched. These aspects include explicit risk management practices. They also include those embedded in managerial tactics (Corvellec, 2009).

According to Kersten (2001), organisations outwardly manifest success. However, inwardly they conceal suppressed tension and become obsessed with rules and the compulsion to control. This highlights the need for a more holistic and balanced way of managing risk.

\section{Research purpose}

Operational risk management is a rational management imperative. However, this does not acknowledge the unconscious role of risk management. In this study, the researchers looked at risk management from a systempsychodynamic perspective. More specifically, its purpose was to describe, using a case study, how anxiety associated with risk management influences the behaviour of people in the banking industry.

An awareness of the unconscious dynamics that underpin managing risk contributed to this study of risk management. Consequently, using the findings of the study, this article provides a more holistic view of risk management.

\section{Trends from the research literature}

\section{A systems-psychodynamic perspective of organisational behaviour}

The primary basis of the systems-psychodynamic perspective is the open systems theory and the application of psychodynamic constructs, like the roles of anxiety and defence mechanisms, on groups and organisations (Gould, 2004). The open systems theory provides the main perspective for understanding the structural aspects of an organisational system (Cilliers \& Terblanche, 2010). One can define a system as a gestalt with clear but permeable boundaries (Kast \& Rosenzweig, 1973). It receives inputs, transforms them and provides outputs to its environment. The focus of a systemic perspectiveis the connection, interaction and interdependency between systems or subsystems (like individuals, groups, parts of an organisation or organisations), the importance of boundaries between systems and subsystems, the role of people within and across boundaries and the nature of the leadership and management of these boundaries (Linklater \& Kellner, 2008; Stacey, 2003).

Organisations are independent external realities that have significant psychodynamic (emotional and psychological) effects on people. Cilliers and Terblanche (2010) refer to this psychodynamic experience as individual experiences and mental processes (like transference, resistance and fantasy) as well as unconscious group and social processes. Cilliers and Terblanche further explain that the main features of the psychodynamic perspective are anxieties and mobilising social defence mechanisms against them. In terms of people's functioning in organisations, mobilising these defences either impedes or facilitates task performance and readiness for change. One can regard the 'boundary' construct as the key one that links the systems perspective and the use of psychodynamic constructs in groups and organisations (McCollom, 1995).

If one views organisations from a systems-psychodynamic perspective, one gets a unique insight into those dynamics that influence the functioning of systems (Cilliers, 2000; Van Eeden, 2010). An awareness of these dynamics could help organisations to improve their capacity to develop task-appropriate adaptations to manage and regulate their behaviours in more rationally appropriate ways (Gould, 2004).

\section{Social systems as a defence against anxiety}

According to Bloom and Farragher (2010), the purpose of defence mechanisms is to create the illusion of certainty and safety to keep us from being overwhelmed by anxiety and helplessness. Jacques (1955) coined the expression 'social systems as a defence against anxiety' to describe the operation of social systems in an industrial setting. Menzies (1960) later applied it to the study of social systems in the nursing service of a general hospital to describe how systems develop mechanisms to defend against the anxiety that comes with change.

The defence mechanisms that Menzies and Jacques described sound similar to those one sees in victims of trauma depersonalisation, denial, detachment, ritualised taskperformance, irresponsibility, idealisation and avoidance of change (Bloom \& Farragher, 2010). They both built on the development theory of Melanie Klein, especially her idea of primitive anxiety and the mental mechanisms in the paranoid-schizoid position (Obholzer, 1999). They applied these concepts to working people who experienced stress as well as to groups and organisations.

Using the differentiation of Bion (1961), between a workgroup and a basic assumption group, the systems-psychodynamic literature accepts the dual function of organisations (Baum, 1987; Gould, 2004; Hirschhorn, 1988; Obholzer, 1999). On the one hand, organisations function in order to perform a 
primary task. They develop strategies, plans and structures to achieve their goals and motivate employees to do their jobs. Organisations seek knowledge, learn from experience and constantly reflect on the best ways to achieve their objectives. One can describe organisations as the ' $\mathrm{ego}^{\prime}$, in terms of Freud's theories, and they function in similar ways to rational, mature people (Rioch, 1975). However, organisations also function, from a systems-psychodynamic perspective, as containers of the anxiety linked to performing their primary functions (Ohman, 2000). The need to avoid anxiety largely forms the nature of organisations. Therefore, one can argue that anxiety underpins behaviour in organisations (James \& Clark, 2002).

Although anxiety in the workplace is, for example, attributed to being part of a group, the environment in which organisations work and to physical and psychological hazards (Obholzer, 1999), it is primarily related to the risk involved in the nature of the work (Stein, 1996). Guerin (1997) points out that all meaningful work implies taking risk because of uncertainty and the need to exercise control.

When the anxiety employees that experience in work situations becomes too great, it triggers unconscious experiences of early infancy. This leads employees to develop defence mechanisms in order to survive (Klein, 1959). Organisations then defend themselves to such an extent that the systems-psychodynamic function of the structures comes to the fore at the expense of supporting their primary tasks. This implies a shift from 'on-task' to 'off-task' functioning (Obholzer, 1999). This is particularly evident in stressful situations, like during periods of organisational change (Cooper, Dewe \& O’Driscoll, 2002). One sees organisations defending themselves against anxiety as spiralling and contagious processes. Their managers, in effect, transfer their anxiety to the organisations' employees (Brooks, 2003). Although these defence mechanisms are necessary for coping with stress, they could prevent organisations from fulfilling their primary tasks and adapting to changing circumstances.

In applying systems-psychodynamic concepts to organisations, Kets de Vries and Miller (1984) used the term 'compulsive organisation' as a type of organisational neurosis to describe organisations where control is the major obsession. Based on a fear of losing control, organisations become obsessed with controlling organisational life and develop extensive formal control mechanisms, like elaborate policies, rules and procedures. Rather than relying on positive human relations, these organisations see all relationships in terms of power and organisational structure and are formalised and hierarchical. The basis of this behaviour is anxiety and it aims to reduce uncertainty. According to Kersten (2001), the structural inequities of organisational relationships in bureaucratic organisations are the basis of neurotic organisational cultures and structures.

However, Stacey (2003) argues that not all organisations that experience high levels of anxiety display social defensive behaviour. These organisations fluctuate between focusing on their primary tasks and using structures to contain anxiety. Stacey also argues that the possibility of containing the level of anxiety seems rooted in the quality of the personal relationships of managers.

Baruch and Lambert (2006) developed a model for managing anxiety in organisations. According to the model, organisations must decide on their reactions to a range of environmental events that might act as stressors, like regulatory changes or economic fluctuations. These materialise in internal changes, like implementing risk management frameworks, which stress and anxiety usually accompany. Baruch and Lambert suggest that the initial organisational appraisal system monitors events as they develop in terms of their effect on the overall functioning of the organisations and their effect on internal management and control structures.

This appraisal may force a review of the primary beliefs and commitments that organisations hold. Their challenge is whether they see events as opportunities or threats. Therefore, the resulting coping behaviour, at organisational level, could consider organisational practice, deny the influences of the events and become unresponsive to both internal and external indictors or move with the changes that the events suggest (Baruch \& Lambert, 2006). A major component in the reactions of organisations is how they manage responses to events. Policies can either promote or inhibit the ability and willingness of organisations to respond to these events, both in their processes and emotional reactions, as organisations and as groups of people who make up the organisations. The complex interaction between these processes, from appraisal to the coping behaviour they adopt, will determine the progress that organisations make and the level of individual and organisational anxiety that results.

The reactions of organisations will also influence their internal and external views of trust in their effective responses to the trigger events and these can have wide-reaching effects (Luhmann, 1979). Trust is a critical variable that influences the performance, effectiveness and efficiency of organisations, whereas lack of trust would create a negative atmosphere in them (Korsgaard, Brodt \& Whitener, 2002; Kramer \& Tyler, 1996; Tzafrir, Harel, Baruch \& Dolan, 2004).

Attempts to manage anxiety in organisations are not always successful and they are even counterproductive at times (James \& Clark, 2002). Nevertheless, the literature suggests that quality relationships (Stacey, 2003), characterised by trust (Korsgaard et al., 2002; Kramer \& Tyler, 1996; Tzafrir et al., 2004) may provide reliable containers of anxiety and assist organisations to focus on their primary tasks.

\section{Risk management as a defence against anxiety}

In this article, the researchers argue that a financial institution doing business in an African country experiences anxiety similar to the anxiety that the nurses, who worked in the hospital that Menzies (1960) studied, experienced. The 
nature of the work involves taking risk - and managing that risk is one of the primary functions of a financial institution. The environment in which the institution works is a different country with an unfamiliar culture. Therefore, it adds to the uncertainty and anxiety (Guerin, 1997).

Taking risk is a core operation and a strategic activity. However, it is also something that the institution has to reduce. This ambiguity may contribute to the development of a social defence mechanism. Hirschhorn (1999), for instance, argued that changing strategies entails significant risk, whilst not changing strategies also creates risk. This ambiguity creates anxiety and, consequently, a defensive fantasy. If the experience of the objective anxiety parallels the unconscious primitive anxiety and related defence mechanisms, the strategies of the institution, like managing risk, will probably serve as a social defence against anxiety. Containing anxiety is a spiralling and contagious process from a systemic perspective (Brooks, 2003). Therefore, managers and employees involved in implementing a risk management framework will apply social defensive mechanisms to deal with anxiety.

James and Clark (2002) show that the benefits of implementing a policy or procedure (like a risk management framework) often look excellent on paper. However, organisations experience difficulty implementing them in practice. This may be the result of overlooking underlying anxieties and not dealing appropriately with them.

The researchers now describe the research design. A report, an interpretation and an integration of the findings follows. They will also discuss the findings, applications and recommendations for future research.

\section{Research design \\ Research approach}

In line with the preference of systems-psychodynamic studies (Gould, 2004), this study used a qualitative, interpretative approach to the investigation of organisational behaviour. Because of the unique contribution of qualitative research to the study of organisational issues, qualitative research is becoming more popular in organisational studies (Brewerton \& Millward, 2001; Cassell \& Symon, 2004; Von Rosenstiel, 2004). It has certain advantages. Firstly, it is a scientific approach to gathering information. Secondly, reflection accounts for the unconscious dynamics (Vanheule, 2002). The primary purpose of the interpretative approach is to describe and understand, instead of explaining and predicting, human behaviour (Babbie \& Mouton, 2001).

\section{Research strategy}

The researchers used the case study method in an attempt to provide a careful description of a single case (Flick, 2004). A case study is appropriate to qualitative research (Lewis, 2003) and is important for organisational research (Locke \& Golden-Biddle, 2002).
The unit of analysis was the individual members involved in operational risk management in a financial institution as the sources of evidence (Babbie \& Mouton, 2001; Flick, 2004).

\section{Research method}

\section{Research setting}

The researchers conducted the research in a bank in an African country. This bank is a subsidiary of a South African bank, which was an acquisition by the South African bank and was previously a national bank. The national culture of the country had changed from a socialist one to include more capitalist elements. Remnants of the socialist culture were still evident in the views of some of the older people in the community.

The institution conformed to the rigorous Basel II-compliant risk management frameworks. Host regulators in the African countries outside of the institution's legal authority had not yet adopted the Basel II framework. Therefore, they placed no legal obligation on any of the subsidiaries to use the strict risk management policies that the South African institution adopted. However, the South African institution applied Basel II in its African operations as the best practice for managing risk.

\section{Entrée and establishing researcher roles}

The South African financial institution requested this research to identify the social, cultural and behavioural factors that influence the implementation of a risk management framework in its African subsidiary. A senior official working for the bank in the foreign country scheduled the interviews. Five academic personnel, two with doctorate degrees, two with master's degrees and one busy with a master's degree, collected the data. At least two were involved in each interview. An official working for the bank in the country was also present during the interviews to introduce the team and to assist respondents to understand the questions and responses. The researchers explained the purpose of the research to the respondents, assured them of confidentiality and anonymity and obtained permission to record the interviews.

\section{Sampling}

The researchers chose purposive sampling as their sampling method and their sample in collaboration with a senior official of the bank working in the foreign country. The interviews involved 39 participants with responsibilities related to risk management.

\section{Data collection methods}

The managers of the subsidiary and the interviewees granted permission to record the interviews and to use the information for research purposes. The researchers conducted semi-structured, in-depth interviews to obtain background information in order to form a general impression of the context and to identify behavioural and operational issues (Babbie \& Mouton, 2001). This allowed them to study the 
social, cultural and behavioural factors that influence the implementation of a risk management framework.

\section{Recording of data}

The researchers recorded the data from all the interviews using a tape recorder and transcribed them.

\section{Data analysis}

The researchers analysed the data using qualitative content analysis (Babbie \& Mouton, 2001; Spencer, Ritchie \& O'Connor, 2003). They used the open coding procedure of grounded theory to assist them with the data analysis in order to identify the highlighted themes.

\section{Strategies employed to ensure quality data}

The five researchers involved in the project developed the interview guide and they mirrored it with a senior member of the bank that sponsored the project. The five researchers (two with extensive systems-psychodynamic training) analysed and interpreted the data. The researchers discussed and compiled the data into a report for the managers of the institution. Three of the researchers reported the findings in this article.

In the light of the character of the dynamics this article has described, the researchers considered possible methodological issues in their decision to use at least two researchers in each interview and to have an official from the local bank present. The researchers used a number of techniques to ensure the quality, credibility, dependability and trustworthiness of the data. They included purposive sampling, protecting confidentiality, transcribing the interviews, iteratively analysing the data and reflections with participants to allow for discussion, feedback and confirmation of the study's findings (Shah \& Corley, 2006; Tracy, 2010). The researchers found that introducing the researchers as coming from a university increased the perceived impartiality and credibility. The local bank official acted as gatekeeper and was very useful in building rapport quickly.

\section{Reporting}

The researchers used a descriptive style of reporting. They attempted to use the same phrases, words and key terms that the respondents used to substantiate the themes.

\section{Findings}

The researchers identified five themes.

\section{Theme 1}

\section{Implementing risk management is associated with high levels of anxiety}

There was evidence that a number of the respondents experienced anxiety about the implementation of the risk management framework. Furthermore, it seemed that the anxiety related to the implementation per se. One respondent mentioned that:

'... to prevent that risk, that's why, that's why we have to introduce several controls to prevent or to, to prevent any loss. Because risk of course goes with a loss ...' (Respondent A, bank employee, African country)

Another respondent linked risk management directly to the safety of the bank by stating:

'This manual says such and such a thing should be done in this way, why? ... You're being told before you open an account you must do this-this-this... It's for the safety, it's for the identification of your customer, we are minimising risk by doing this ... this to you and to the customer too.' (Respondent B, bank employee, African country)

The expectations of the culture of the officials' community also added to the experience of anxiety. For example, one of the respondents stated:

'Actually, the culture itself is the fear that is within an individual ... He sees something which is not right being done, but he feels telling somebody that there is somebody doing something wrong, you know.' (Respondent C, bank employee, African country)

Employees also experience anxiety because of uncertainty about their own futures. One respondent mentioned:

'... it was really tough because staff did not know their fate what will happen? Some people are coming to take their bank, what will be the fate of our employment? We are used to live like this, now some people are coming to take the bank - fear of the unknown. People did not know what will happen, so that one also blows the resistance and because the public itself was negative, so even the workers.' (Respondent D, bank employee, African country)

Another respondent expressed a source of anxiety as:

'... the older generations ... first of all, I think most of them fear - if I may use that word - they fear to be indebted to the banks and all that.' (Respondent E, bank employee, African country)

\section{Theme 2}

\section{A split is experienced between managers and employees}

There is enough evidence to substantiate that respondents experienced a split between managers in South Africa and the subsidiary bank. Respondents verbalised strong feelings about managers:

'... sometimes we feel that, okay, these guys don't trust us. ... then it must mean they think we are lying to them. Like we are telling this is the situation and they still saying no. So then sometimes we get to think they don't trust us, us we not trusted, we are pulling things from the air.' (Various respondents who participated in study, bank employees, African country)

These words echo the same sentiment:

'When they came in, the staff treated the investor, the foreigners, like enemies. So everybody ... management treats staff as enemies and staff treat top management as enemies. People therefore feel alienated from management; now the staff they don't feel like they are part of the bank ... what I've noticed that, top management is not very close to the staff and that gap is widening.' (Various respondents who participated in study, bank employees, African country) 


\section{Theme 3}

\section{Risk management is experienced as excessive control}

With regard to the implementation per se, respondents experienced the introduction of risk management as a form of control, most probably because of the novelty of risk management in the country and the nature of risk management itself. Several interviewees acknowledged concerns about control:

'We still trying to teach them, to make them understand because we need to make them understand, we need to put controls. We need to see where the risks, and the risks also, you need to know which risk is actually, the actual risk that you need. Cause you may have risk that does not fall under the risk as it is defined. So those are the issues that we are still battling with the people but risk is there and we are managing it.' (Various respondents who participated in study, bank employees, African country)

Some respondents even questioned the perceived excessive control:

'They came in to run a business, ok and as a business owner you have your own ways of looking at business, putting up controls, ok. Having systems that you want and putting things the way you want is how you want your business to go and that is what happened.' (Various respondents who participated in study, bank employees, African country)

and

'Now, what has happened is, there's a lot of effort being spent on risk and control - if it's for the good and the bad we can discuss. There's a lot of policies being implemented ...' (Various respondents who participated in study, bank employees, African country)

Another respondent described the experience of risk management as:

'... you have processes and procedures that you also need to change because whatever you are doing must go in line with the system. So we went through putting up process, procedure in manuals form, in circulars, telling people of what they are required to do. What are the controls, I mean, actually need to look at. They must not do this, they must do this.' (Respondent F, bank employee, African country)

\section{Theme 4}

\section{Risk management minimises the human element}

Respondents experienced the minimisation of the human element because of risk management. This might lead them to avoid taking personal ownership of risk management. One respondent refers to the experience of risk management as:

'First, risk management ... to me it's just paperwork at the moment. That's why I was even telling you about; we just have a file and then we'll just talk to the manager, your RCA's are due for the quarter. To me, that's how I see it, it's just paperwork and documentation.' (Respondent G, bank employee, African country)

Another noted, with regard to its effectiveness:

'No, ... it's just something that you have there in the file and no-one uses it, no-one can have access to it. It's just a document then. It just becomes a document, it's just something that, okay fine, we're going to be audited at some point, we have to have this, these things have to be in place, so they're in place ...' (Respondent $\mathrm{H}$, bank employee, African country)

Another respondent described the experience as:

'So you end up being like a ... you are not running the business anymore, you are shifting to try and meet the compliance criteria. You are shifting your whole mind is trying to meet this standard.' (Respondent I, bank employee, African country)

The words of another respondent echoed this experience:

'No, we usually tell them how to manage such risks, for example, through procedures, to ensure procedures are in place and monitor the things that we can prevent from happening by following the procedures. And certain small things that might happen, but we can mitigate them by let's say risk transfer, for example through insurance, things like that. So we highlight those areas and get them that ... even though we cannot control them and we cannot put in some measure to prevent them, but we can ensure that we are safeguarded by transferring the risk.' (Respondent J, bank employee, African country)

A possible consequence of minimising the human element might be that employees avoid taking personal ownership for managing risks. For example, one respondent mentioned that:

'... if the strategy of the bank, the top management of the bank doesn't even know the strategy of the bank, how do you expect people to 'own' what they're doing? That's where the problem is.' (Respondent $\mathrm{K}$, bank employee, African country)

\section{Theme 5}

\section{Implementing risk management influences the relationship with clients negatively}

There is enough evidence to postulate that there is anxiety about relationships that were previously based on trust will now be based on fear. Therefore, it seems that the risk related to the execution of the primary task has become a risk of breaking relationships between members of the same national culture.

Several participants indicated that trust plays a pivotal role in the country's culture when the institution lends money:

'... we trust each other and as I've said in most cases we borrow money based on trust. So the factor there, the social cultural factor is, is influencing that borrowing ... I think its trust. ' (Various respondents who participated in study, bank employees, African country)

One respondent expressed the anxiety about relationships as:

'Fear about breaking down the relationship with that particular person that he have lived for quite some time. Fear about now going back to the public and him being said: $\mathrm{Ha}$, you know that is the guy who went and mentioned my name to this people .... because [we] are people that have lived together, doing things together. That is the culture and that confidence of coming up front and holding one's head and saying what is not right that is not there. And when you don't have that in people's mind, the risk becomes very difficult to manage.' (Respondent L, bank employee, African country) 
Referring to the influence of risk management on clients, one respondent, for example, mentioned that 'I've gone to customers and they're complaining about this, why are we doing this?'

\section{Discussion}

The aim of the article was to describe, using a case study, how the anxiety that relates to risk management influences the behaviour of people in a financial institution that does business in an African country. There was evidence that introducing risk management is associated with high levels of anxiety. Consistent with the literature, the researchers found that one could ascribe anxiety, on an objective level (Menzies, 1975), to a number of factors or a combination of them, like:

- the nature of the implementation per se (Stein, 1996)

- the safety of the bank - in terms of preventing losses (Hirschhorn, 1999; Ohman, 2000)

- the expectations of the community (Kersten, 2001)

- uncertainty about the future (Cooper et al., 2002).

The researchers argued that the high objective risk in this case study triggered unconscious experiences of anxiety and that the institution introduced mechanisms as social defences to deal with and contain the anxiety. This resulted in a negative influence on identifying, or dealing with, the primary function as it relates to the strategy of the institution.

The literature substantiates this argument. It shows that, at a collective level, when objective anxiety is too high it triggers earlier unconscious anxiety and uses social defence mechanisms to contain the anxiety (Brown \& Starkey, 2000; De Board, 1978; Fineman, 1996; Hirschhorn \& Young, 1991; Kets de Vries \& Miller, 1984; Ohman, 2000). Themes two to five illustrate defensive methods of dealing with social anxiety.

One of the major sources of anxiety is the relationship between the managers in South Africa and those in the subsidiary. One way they are dealing with the anxiety is by creating a split between them. The researchers discussed this finding in theme two. According to the literature, splitting is a defence mechanism (Klein, 1959) that groups use to split the world into subgroups of friends and enemies where subgroups may gang up against the authority figure or perceived aggressor. This results in intra- and inter-group conflict (Erlich, 2001; Kets de Vries, 2006). The external risks that this institution faces then become internal threats (Hirschhorn, 1997).

Another way the institution is dealing with the anxiety is by placing too much emphasis on control. The researchers discuss the experience of risk management, as an excessive form of control, in theme three. This is consistent with the literature (Hirschhorn, 1997; Van Eeden, 2010). It shows that managers may exercise too much control over employees because the external risks of the organisation frighten them and because they cannot control the external reality. The researchers argue that, because employees experience risk management frameworks as forms of control, these frameworks are not conducive to managing risk. They are merely mechanisms to contain the anxiety. Therefore, the institution could lose much of the value that it could gain from subjective aspects, like using relationships to manage risk.

Control mechanisms, like risk management frameworks, represent managers in the unconscious minds of the employees who work in the subsidiary. According to Hirschhorn (1997), threats and risks always mobilise fantasies about relationships with authority figures and their representation in rules, schedules, procedures and divisional boundaries. In this case, employees could transfer the aggression that they aimed at managers onto the framework and into rebellious behaviour against its implementation. Voyer, Gould and Ford (1997) suggest that an organisation's overreliance on, and implementation of, defence mechanisms to control organisational anxiety often amplifies the anxiety instead of containing it.

With the emphasis on regulatory and control mechanisms, the researchers also found that the financial institution deals with anxiety by depersonalising risk management. According to Kets de Vries and Miller (1984), compulsive organisations rely on formal controls rather than on positive human relations. This causes a loss of personal involvement. If organisations depersonalise risk management, ownership of the risk management framework remains with managers. Employees will comply without question and leave no room for judgement and intuition. There is no reflection on problems and events, which stifles problem solving in organisations (Brooks, 2003; James \& Clark, 2002). Furthermore, Hirschhorn (1997) argues that when organisations depersonalise decision-making, personal accountability for decisions is lost and people feel less responsible for the consequences of these decisions.

Finally, the researchers provided evidence for the belief that risk management influences relationships with clients negatively. A trusting relationship is highly valued in the foreign country. Employees expressed the fear that risk management would negatively affect this relationship. Therefore, the split that employees experience between managers and the subsidiary provided a fertile environment for aligning with the clients against managers. One can probably ascribe this behaviour to the experience of structural inequities between the South African managers and those of the subsidiary and particularly to the differences between their experiences of socialism and a capitalistic management style (Kersten, 2001). When splits occur, in-group out-group divisions form and mobilise aggressive forces against the 'enemy'. This strengthens the identity of the group or subgroup (Kets de Vries, 2004; Neumann, 1999; Stokes, 1994).

The literature argues that managers drive effective risk management and employees adhere to it (Jain, 2010). One can also regard the distance between managers and employees in the African subsidiary as a managerial defence against the anxiety related to the risk of creating trusting relationships with people in the foreign country. Keeping this dynamic 
intact enables managers to transfer their own anxieties onto the employees in the African country. They carry it on behalf of their managers. As a spiralling process (Brooks, 2003), they then have to deal with their own anxieties and with those of their managers. Keeping this dynamic intact is also consistent with Sigmund Freud's idea of repetition compulsion - people put themselves in stressful situations in order to regress to familiar past experiences (Stein, 2004). Therefore, the employees in the foreign country display defensive behaviour. This is clear in the themes the researchers identified.

One can also ascribe this dynamic to the fundamentally compulsive culture and structure that is typical of bureaucratic organisations. Managers working in a society that has a culture and structure pre-occupied with perceiving problems in terms of control, conflict and suspicion will probably keep this dynamic intact (Kersten, 2001). This is especially true when a subsidiary with less power and a socialist background confronts its managers.

In conclusion, the premise the researchers formulated is that the objective anxiety employees experience in the banking industry triggers the unconscious anxiety and related defence mechanisms similar to those Menzies (1975) identified in the hospital. On the one hand, financial institutions have to take risks in order to do business. On the other hand, taking risks has a negative influence on the people implementing the risk management framework and their clients. This objective dynamic resembles the unconscious life and death instincts that Sigmund Freud identified and Klein (1959) applied in her development theory. Together with the anxiety that relates to the uncertainty of doing business in a foreign African country, the developing theme is that risk management serves as a social defence against anxiety.

\section{Implications of the study}

The findings have a number of practical implications. Managers of financial institutions doing business in African countries should assess their own levels of anxiety and those of their employees. This will allow managers to introduce mechanisms that will contain their own anxiety and the anxiety of their employees. Creating a trusting relationship, whilst implementing an operational risk management framework, is an example of an appropriate intervention. Therefore, instead of viewing the human factor as a possible source of risk, managers can capitalise on the human factor to improve the effectiveness of the risk management framework.

Mechanisms to contain anxiety might put managers in a tricky position. They can deal with the unconscious dynamics by building relationships with employees as well as by capitalising on the human element and the relationships that these employees have with their clients. However, building relationships might increase anxiety because engagement is also a source of anxiety in systems-psychodynamic relationships (Krantz, 2001). This might be especially relevant during the transition phase. Therefore, organisations should introduce mechanisms to reduce the loss of established social defences and consolidate a new, more holistic and realistic way of managing risk.

\section{Limitations of the study}

The researchers did not include managers from the South African institution in the sample. Including them could have helped the researchers to determine the extent to which managers transferred their aggression to the employees working in the subsidiary.

\section{Recommendations for future research}

The researchers recommend that attempts should be made to duplicate the findings in other financial institutions as well as in other sectors of industry that are doing business in African countries.

Managing risk is complex. This article adds another dimension that one must consider. This is that risk management can work against the primary task of doing business by functioning as a social defence mechanism. If one views risk management from a systems-psychodynamic perspective, one could add a valuable element to managing risk. If banks do not take risks, they will go out of business. However, if they do take risks, they might also go out of business if they do not manage the risks in appropriate and holistic ways.

\section{Acknowledgements Competing interests}

The authors declare that they have no financial or personal relationship(s) that may have inappropriately influenced them in writing this paper

\section{Authors' contributions}

D.G. (UNISA), M.L. (UNISA) and A.v.N. (UNISA) were responsible for the design and research. Annelize van Niekerk made conceptual contributions. Dirk Geldenhuys and Madia Levin wrote the manuscript.

\section{References}

Andersen, T.J. (2006). Perspectives on strategic risk management. Copenhagen: Copenhagen Business School Press.

Babbie, E., \& Mouton, J. (2001). The practice of social research. Cape Town: Oxford University Press.

Baruch, Y., \& Lambert, R. (2006). Organizational anxiety: applying psychological concepts into organizational theory. Journal of Managerial Psychology, 22(1), 84-99. http://dx.doi.org/10.1108/02683940710721956

Basel Committee. (2006). Core Principles for Effective Banking Supervision. Basel, Switzerland: Bank for International Settlements.

Baum, H. (1987). The invisible bureaucracy: The unconscious in organizational problem solving. New York: Oxford University Press.

Bion, W.R. (1961). Experiences in groups. London: Tavistock. http://dx.doi. org $/ 10.4324 / 9780203359075$

Bloom, S.L., \& Farragher, B. (2010). Destroying sanctuary: The crisis in human service delivery systems. New York: Oxford University Press.

Brewerton, P., \& Millward, L. (2001). Organizational research methods. London: Sage. 
Brooks, I. (2003). Systemic Exchange: Responsibility for Angst. Organization Studies, 24(1), 125-141. http://dx.doi.org/10.1177/0170840603024001682

Brown, A.D., \& Starkey, K. (2000). Organizational identity and learning: a psychodynamic perspective. Academy of Management Review, 25(1), 102-132. http://dx.doi. org/10.2307/259265, http://dx.doi.org/10.5465/AMR.2000.2791605

Butler, D., (2010). The downside of recovery: The new business risk landscape in 2010 Management Today, 28(2), 60-62

Cassell, C., \& Symon, G. (Eds). (2004). Essential guide to qualitative methods in organizational research. London: Sage.

Cilliers, F.v.N. (2000). Team building from a psychodynamic perspective. Journal of Industrial Psychology, 26(1), 18-23.

Cilliers, F.v.N., \& Terblanche, L. (2010). The systems psychodynamic leadership coaching experiences of nursing managers. Health SA Gesondheid 15(1). Retrieved September 11, 2011, from http://www.hsag.co.za/index.php/HSAG/ article/view/457/479

Cooper, C.L., Dewe, P.J., \& O’Driscoll, M.P. (2002). Organizational stress: A review and critique of theory, research, and applications. Thousand Oaks: Sage.

Corvellec, H. (2009). The practice of risk management: Silence is not absence. Risk Management, 11(3-4), 285-304. http://dx.doi.org/10.1057/rm.2009.12

De Board, R. (1978). The psychoanalysis of organizations: A psychoanalytic approach to behaviour in groups and organizations. London: Tavistock.

Erlich, H.S. (2001). Enemies within and without: Paranoia and regression in groups and organizations. In L. Gould, L.F. Stapley \& M. Stein (Eds), The systems psychodynamics of organizations (pp. 115-131). London: Karnac Books.

Fineman, S. (1996). Emotional Subtexts in Corporate Greening. Organization Studies, 17, 479-500. http://dx.doi.org/10.1177/017084069601700306

Flick, U. (2004). Design and process in qualitative research. In U. Flick, E. von Kardorff \& I. Steinke (Eds), A companion to qualitative research (pp. 146-152). London: Sage.

Gould, L.J. (2004). Fraternal disciplines: Group relations training and systems psychodynamic organizational consultation. In L.J. Gould, L.F. Stapley \& M. Stein (Eds), Experiential learning in organizations (pp. 37-61). London: Karnac.

Guerin, B. (1997). The social context of communication: Communicative power as past and present social consequences. In J. Owen (Ed.), Context and communication behavior (pp. 133-179). Reno, NV: Context Press.

Hirschhorn, L. (1988). The workplace within: Psychodynamics of organizational life. Cambridge, MA: MIT Press.

Hirschhorn, L. (1997). Reworking Authority: Leading and following in the Post-Modern Organisation. Cambridge, MA: MIT Press.

Hirschhorn, L. (1999). The Primary Risk. Human Relations, 52(1). 1999. http://dx.doi. org/10.1177/001872679905200102

Hirschhorn, L., \& Young, D. (1991). Dealing with the anxiety of work: Social defences as coping strategy. In M.F.R. Kets de Vries (Ed.), Organizations on the couch: Clinical perspectives on organizational behaviour and change (pp. 215-240). San Francisco: Jossey-Bass.

Hubbard, D.W. (2009). The failure of risk management: Why it's broken and how to fix it. Hoboken, New Jersey: John Wiley \& Sons.

Jacques, E. (1955). Social systems as a defence against persecutory and depressive anxiety. London: Tavistock Publications.

Jain, A. (2010). Operational Risk Management (ORM) in Banks and Financial Institutions. Roadmap to Advanced Measurement Approach (AMA) and Better Business Performance. MetricStream. Retrieved October 19, 2010, from http:// www.metricstream.com/solution briefs/ORM.htm

James, K., \& Clark, G. (2002). Service organisations: issues in transition and anxiety containment. Journal of Managerial Psychology, 17(5), 394-407. http://dx.doi. org/10.1108/02683940210432637

Kast, F.E., \& Rosenzweig, J.E. (1973). General systems theory: Applications for organization and management. In F.E. Kast \& J.E. Rosenzweig (Eds), Contingency views of organization and management (pp. 37-56). Chicago: Science Research Associates.

Kersten, A. (2001). Organizing for powerlessness: A critical perspective on psychodynamics and dysfunctionality. Journal of Organizational Change Management, 14(5), 452-467. http://dx.doi.org/10.1108/EUM0000000005877

Kets de Vries, M.F.R., \& Miller, D. (1984). The neurotic organization: Diagnosing and changing counterproductive styles of management. San Francisco: Jossey-Bass.

Kets de Vries, M.F.R. (2004). Struggling with the demon: Perspectives on individual and organizational irrationality. Madison, CT: Psychosocial Press.

Kets de Vries, M.F.R. (2006). The leader on the couch: A clinical approach to changing people and organisations. Chichester: Wiley \& Sons.

Klein, M. (1959). Our adult world and its roots in infancy. Human Relations, 12, 291303. http://dx.doi.org/10.1177/001872675901200401
Korsgaard, M.A., Brodt, S., \& Whitener, E. (2002). Trust in the face of conflict: The role of managerial trustworthy behavior and organizational context. Journal of Applied Psychology, 87, 312-319. http://dx.doi.org/10.1037/0021-9010.87.2.312

Kramer, R.M., \& Tyler, T.R. (Eds). (1996). Trust in organizations: Frontiers of theory and research. Thousand Oaks, CA: Sage Publications.

Krantz, J. (2001). Dilemmas of organizational change: A systems psychodynamic perspective. In L.J. Gould, L.F. Stapley \& M. Stein (Eds), The systems psychodynamics of organizations: Integrating the group relations approach, psychoanalytic, and open systems perspectives (pp. 133-156). London: Karnac.

Lewis, J. (2003). Design issues. In J. Richie \& J. Lewis (Eds), Qualitative research practice (pp. 47-76). London: Sage.

Linklater, J., \& Kellner, K. (2008). Don't just do something ... stand there: using action learning to help organisations work with anxiety. Action learning: Research and Practice 5(2), 167-172. http://dx.doi.org/10.1080/14767330802185855

Locke, K., \& Golden-Biddle. (2002). An introduction to qualitative research: Its potential for industrial and organizational psychology. In S.G. Rogelberg (Ed.), Handbook of research methods in industrial and organizational psychology (pp. 99-118). Malden, MA: Blackwell Publishers.

Luhmann, N. (1979). Trust and power. Chichester: Wiley.

McCollom, M. (1995). Group formation: Boundaries, leadership and culture. In J. Gillette \& M. McCollom (Eds), Groups in context: A new perspective on group dynamics. Lanham: University Press of America.

Menzies, I.E.P. (1960). A Case-Study in the Functioning of Social Systems as a Defence against Anxiety: A Report on a Study of the Nursing Service of a General Hospital. Human Relations, 13, 95-121. http://dx.doi.org/10.1177/001872676001300201

Menzies, I.E.P. (1975). A case study in the functioning of social systems as a defense against anxiety. In A.D. Colman \& W.H. Bexton (Eds), Group relations reader 1 (pp. 281-312). Jupiter, FL: A.K. Rice Institute.

Neumann, J.E. (1999). Systems psychodynamics in service of political organizational change. In R. French \& R. Vince (Eds), Group relations, management, and organization (pp. 54-69). New York: Oxford University Press.

Obholzer, A. (1999). Managing the unconscious at work. In R. French \& R. Vince (Eds) Group relations, management and organization (pp. 112-126). New York: Oxford.

Ohman, A. (2000). Anxiety. In G. Fink (Ed), Encyclopedia of stress. San Diego: Academic Press.

Rioch, M.J. (1975). The work of Wilfred Bion on groups. In A.D. Colman \& W.H. Bexton (Eds), Group relations reader 1 (pp.21-33). Washington: A.K. Rice Institute.

Shah, S.K., \& Corley, K.G. (2006). Building better theory by bridging the quantitativequalitative divide. Journal of Management Studies, 43(8), 1821-1835. http:// dx.doi.org/10.1111/j.1467-6486.2006.00662.x

Spencer, L., Ritchie, J., \& O'Connor, W. (2003). Analysis: Practices, Principles and processes. In J. Ritchie \& J. Lewis (Eds), Qualitative research practice: A guide for social science students and researchers (pp. 199-218). London: Sage.

Stacey, R.D. (2003). Strategic management and organizational dynamics: The challenge of complexity. (4th edn.). Harlow, England: Pearson Education.

Stein, M. (1996). Unconscious phenomena in work groups. In M.A. West (Ed.) Handbook of work group psychology (pp. 143-158). Chichester: Wiley \& Sons.

Stein, M. (2004). Theories of experiential learning and the unconscious. In L.J. Gould, L.F. Stapley \& M. Stein (Eds), Experiential learning in organisations (pp. 19-36). London: Karnac.

Stokes, J. (1994). Institutional chaos and personal stress. In A. Obholzer \& V.Z. Roberts (Eds), The unconscious at work: Individual and organizational stress in the human services (pp. 122-128). London: Routledge.

Tracy, S.J. (2010). Qualitative quality: Eight "big-tent" criteria for excellent qualitative research. Qualitative Inquiry, 16(10), 837-851. http://dx.doi. org/10.1177/1077800410383121

Tzafrir, S.S., Harel, G., Baruch, Y., \& Dolan, L.S. (2004). The consequences of emerging HRM practices for employees trust in their managers. Personnel Review, 33(6), 628-647. http://dx.doi.org/10.1108/00483480410561529

Vanheule, S. (2002). Qualitative research and its relation to Lacanian psychoanalysis. Journal for the Psychoanalysis of Culture \& Society, 7(2), 336-343.

Van Eeden, R. (2010). Exploring the development of an organisational culture of control and dependency from a systems psychodynamic perspective. SA Journa of Industrial Psychology, 36(1), Art. \#854, 11 pages. DOI: 10.4102/sajip.v36i1.854

Von Rosenstiel, L. (2004). Organizational analysis. In U. Flick, E. von Kardorff \& I. Steinke (Eds), A companion to qualitative research (pp. 129-136). London: Sage.

Voyer, J.J., Gould, J.M., \& Ford, D.N. (1997). Systemic Creation of Organizational Anxiety: An Empirical Study. Journal of Applied Behavioral Science, 33, 471. http:// dx.doi.org/10.1177/0021886397334004 